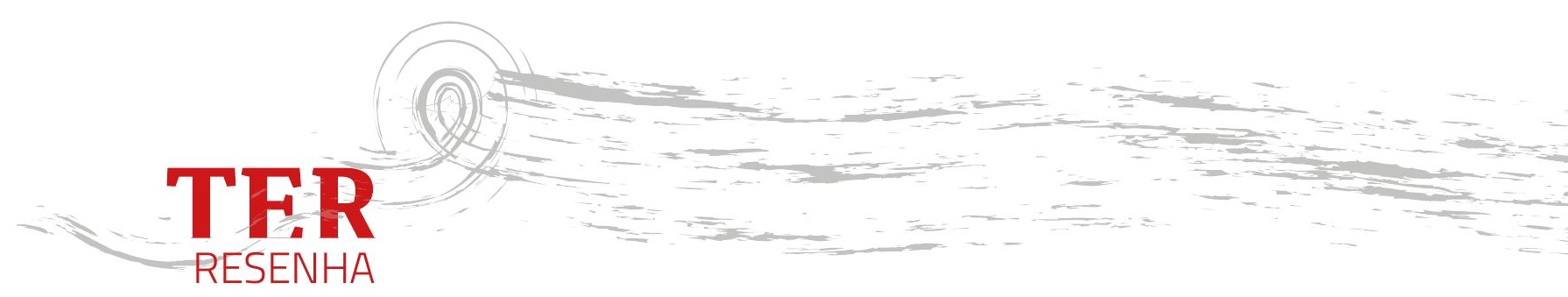

Universidade de São Paulo,

ALEXANDRE ARAÚJO BISPO

São Paulo, Brasil.

\title{
OBJETO AFETIVO: \\ USOS SOCIAIS, TEMPO \\ E FOTOGRAFIAS COMENTADAS
}

Dorrit Harazim. 2016. $O$ instante certo. São Paulo, Companhia das Letras, 384p. o que torna uma foto publicável? Essa parece ser a pergunta fundamental de $O$ instante certo, primeiro livro da jornalista Dorrit Harazim (2016). A obra reúne artigos originalmente publicados entre 1995 e 2016 em revistas como Zum ${ }^{1}$, os quais cobrem múltiplos interesses da autora: artes visuais, guerras, política, luta por direitos civis, gênero. $\mathrm{O}$ volume conta histórias de imagens e de pessoas e pode ser lido de três modos: como uma exposição, como documento probatório de um arquivo pessoal e como álbum de família.

1. Disponível em: <http://revistazum.com.br/en/revista-zum>. Acesso em: 5 dez. 2017. 


\section{FOTÓGRAFOS EM EXPOSIÇÃO}

Visto como uma exposição de fotos, o livro exibe uma série de imagens (icônicas ou não) que ultrapassaram seu momento de produção. Visto como documento em um arquivo pessoal, sua reunião de textos reflete momentos da vida profissional da jornalista, que recebeu prêmios como o Gabriel Garcia Márquez de Jornalismo na categoria Excelência². Como álbum de família, apresenta uma sequência de fotografias que, à medida que são comentadas, nos levam a pensar sobre a presença e participação das imagens na vida social, quando certas fotos se mostram capazes de conduzir a mudanças importantes no curso da história.

Cada um dos 38 artigos que compõem o volume poderá ser livremente desmembrado do conjunto sem perdas para a compreensão do pensamento interessado de Harazim nas fotografias e suas histórias de vida: produção, publicação, circulação, usos sociais e descarte. Embora fale de fotos, $O$ instante certo não é um fotolivro no qual poderíamos cotejar diferentes imagens, como no perturbador Big Book, de W. Eugene Smith. Bom motivo para Dorrit Harazim discutir a obra do autor em "O triunfo de W. Eugene Smith" (2016, 211-220), artigo no qual o Big Book figura como um ato radical de autonomia e liberdade criativa quanto à forma e ao conteúdo.

Ao brasileiro "Assisinho", como chama o fotógrafo mineiro, Harazim dedica o ensaio "O clique único de Assis Horta" (Ibid., 31-45), afirmando que ele "deu rosto, identidade e visibilidade fotográfica ao trabalhador. Alforriou-o do anonimato, revelando-o como classe e como indivíduo na história visual do país" (Ibid., 34). Gente simples, muitos dos retratados são negros, fato que aponta para um processo de integração social pelo consumo visual fotográfico ainda pouco conhecido pela história da fotografia no Brasil. Há ainda um senso comum que tende a sugerir que pessoas negras, mesmo em ambiente urbano, não acessariam a fotografia como um bem visual importante, sobretudo no plano das narrativas familiares. Nesse sentido, o acervo de negativos de Horta mostra como o retrato $3 \times 4$ obrigatório serviu de porta de entrada para o consumo de outras imagens individuais e coletivas, transformando os modos de exprimir e memorizar os vínculos afetivos entre pessoas.

A relação entre pessoas negras e estúdios fotográficos aparece também em "Estúdio Malick" (Ibid., 311-320), que discute a obra do africano Malick Sidibé. o retratista do Mali produziu retratos de uma era em que seu país se tornara uma jovem e eufórica nação independente, a partir de 1960.

2. Para a teoria arquivística, os documentos dos arquivos pessoais refletem as atividades de seus titulares, entre as quais, no caso de certos profissionais, sua produção intelectual. Ver a esse respeito Travancas, Rouchou e -Heymann (2013) e Camargo e Goulart (2007). 
Também negro, o sul-africano Koto Bolofo fotografou não a plenitude da vida, mas a expressão da violência pelas imagens que fez da velha prisão de Robben Island, onde esteve preso Nelson Mandela. No ensaio "Retrato invisível" (Ibid., 289-294) a autora toma essas fotos de Bolofo para pensar sobre os horrores do apartheid também no plano visual, quando fotos do líder foram proibidas de circular. Essa repressão às imagens faz pensar sobre as condições em que uma fotografia se torna impublicável. Harazim ensina que a ausência de imagens de Mandela preso deixa entrever como a fotografia poderia salvaguardar a verdade de seu encarceramento, daí a preocupação com o apagamento visual da memória do líder negro.

Em "A cor de Gordon Parks - Parte I" e "Gordon Parks na catacumba Parte II" (Ibid., 175-192), comenta que esse famoso fotógrafo negro norte-americano trabalhou durante anos para a Life, quando fez, em 1956, a série colorida Segregation Story, que documenta o dia a dia dos Thornton, uma família negra do Alabama. Diante do grande volume de vendas, 13,5 milhões de exemplares, Harazim mostra que o sucesso se devia ao impacto entre o público branco da revista em ver uma família negra no "essencial igual à dele" (Ibid., 179)3.

\section{UM ÁLBUM DE FAMÍLIA: ESQUECIMENTO, MEMÓRIA E MULHERES}

Se $O$ instante certo pode ser visto tanto como uma exposição imaginária a inspirar mostras futuras no Brasil, quanto como um arquivo pessoal, porque reflete e permite acompanhar alguns momentos da carreira profissional da autora, perscrutá-lo corresponde a folhear um álbum de família, dispositivo no qual cada foto, ao ser mostrada por aqueles que detêm sua guarda, não raro é acompanhada de falas que oralizam o que se vế. Esse ato de falar das imagens revela que elas não são um objeto exclusivamente feito para olhos passivos, dispostos a contemplá-las em silêncio. Tais imagens mobilizam outros sentidos, tanto assim que podemos escrever a seu respeito, e essa escrita interfere no modo como serão apreendidas. Ao folhear $O$ instante certo como álbum, ficamos sabendo sobre planos, materiais e procedimentos da arquitetura nazista construída entre 1943 e 1945 em "A muralha esquecida" (Ibid., 169-173);

3. Dois outros fotógrafos negros citados são o nigeriano Teju Cole e o norte-americano Roy DeCarava $(2016,129)$.

4. Ver o balanço de Edwards (2012) acerca da bibliografia sobre os apelos sensoriais das imagens fotográficas, especialmente a oralidade e o tato. Ver Bruno (2009), que discute a relação verbal-visual no estudo que fez sobre acervos fotográficos de pessoas idosas. Em diálogo com seus interlocutores, a autora monta arranjos visuais a partir dos acervos dos informantes. Também Leite (2001) pode ser consultada nesse sentido, pois considerou as narrativas orais em suas pesquisas sobre fotos de família. 
sobre o porquê de um museu decidir chamar um fotógrafo para documentar suas ruínas; ou, ainda, tomamos conhecimento de que o apartheid inaugurou em 1976, em uma zona branca de Joanesburgo, o edifício cilíndrico de 54 andares e 467 apartamentos - Ponte City - por meio do texto "Autópsia de uma ilusão" (Ibid., 89-95), em torno do qual Harazim comenta o monumental trabalho do fotógrafo Mikhael Subotzky e do artista Patrick Waterhouse. Juntos, eles coletaram e documentaram minuciosamente a vida de um dos maiores símbolos da "utopia da supramacia branca" (Ibid., 91).

Ainda seguindo a lógica de um álbum familiar repleto de histórias e feitos da humanidade, Harazim pontua: Evelyn MacHale trazia junto de si "uma nécessaire com fotos de família" (Ibid., 15) antes de se suicidar. Esse apego às imagens afetivas lembra uma observação de Walter Benjamin sobre nossa relação com fotos: "Nenhuma obra de arte é contemplada tão atentamente em nosso tempo como a imagem fotográfica de nós mesmos, de nossos parentes próximos, de nossos seres amados" (1994, 103).

Aqueles que em algum momento da vida passaram pela fotografia são o assunto do fotógrafo polonês Jerry Lewczynski, que, segundo o acertado título do artigo "O catador de imagens" (2016, 203-210), tornou-se, por piedade com desconhecidas pessoas de retratos, um tipo particular de lixeiro. Aqueles que se foram, mas que permanecem pelas fotos, parecem querer voltar à vida. As imagens que interessavam ao catador, porém, gozam de pouco prestígio social quando se desprendem de seus proprietários. São imagens não icônicas, em geral seriadas, sem legendagem $^{5}$, de enquadramento previsível e simples, às vezes borradas e o mais importante, remetem a pessoas sem notoriedade ${ }^{6}$. São homens e mulheres sobre os quais restaram imagens que poderiam ser facilmente esquecidas, como o foram as pessoas descritas por meio de seus pertences em "Viagem sem volta" (Ibid., 67-75). Esse ensaio descreve um projeto de Jon Crispin, que fotografou 429 malas guardadas até 1995 em um sótão do Willard Lunatic Asylum de Nova York. Ambos os fotógrafos estão preocupados com a perda e o esquecimento, com o lixo e a memória. Esse número de "caixas de memória" agora publicizadas não perfaz, contudo, $10 \%$ do total de indivíduos que por ali passaram durante quase um século.

\footnotetext{
5. Para Harazim as legendas, quando informativas, como as usadas pelo fotógrafo Joseph Koudelka, possibilitam "ver além da imagem" $(2016,286)$.

6. Na minha pesquisa de mestrado trabalhei com esse tipo de imagem. Cf. Bispo (2012).

7. Segundo Assmann (2011, 125), as caixas de memória são dispositivos para guardar o que se considera importante, como documentos e tesouros.
} 
Pouco mais de $10 \%$ do livro de Harazim traz na abertura dos ensaios duas fotos, como os artigos "A história em preto e branco" (Ibid., 121-130), "Loving Story" (Ibid., 321-332), "A fotografia descobre a América” (Ibid., 333340), "O cidadão Meeropol" (Ibid., 355-366) e, finalmente, "As novas cores do império russo” (Ibid., 147-154). Apesar disso, por um artifício próprio à natureza do texto escrito, Harazim multiplica imagens pela escolha de uma ou duas para abrir cada texto e pela remissão a muitas outras. Um exemplo é o retrato de Liev Tolstói (Ibid., 150) feito pelo pioneiro da cor no já decadente império russo, Sergei Mikhailovich Prokudin-Gorskii. Outra multiplicação ocorre com "Tomoko no seu banho". A única fotografia, segundo a autora, que W. Eugene Smith "teve orgulho pleno" de ter feito. Para Stefânia Bril $(1987,40)$, a foto da menina no banho era uma prova da vitória de Smith na luta, lá no Japão, em Minamata junto com os pescadores. Ao argumentar que uma fotografia vai além do instante selecionado no tempo, Harazim nos conduz por histórias envolventes, observando pelas imagens que seleciona os momentos de produção, circulação e usos, inclusive contraditórios com as intenções dos produtores e de seus retratados. Exemplar, nesse sentido, é "Ruth Orkin fez primeiro e melhor" (2016, 131-137), em que Harazim narra simultaneamente a história de duas mulheres - a fotógrafa Ruth Orkin e a modelo Ninalee Allen - e mostra como uma cantada a uma mulher andando sozinha livremente em uma rua italiana, publicada em 1952, tornou-se vinte anos depois símbolo de opressão machista na óptica da segunda onda feminista pós década de 1960. Resulta dessa reflexão que, mais do que restituir uma verdade essencial à imagem intitulada American Girl in Italy, o que mais interessa ao seguir seu argumento é que as fotografias surgem com biografia e trajetória próprias, transcendendo os personagens envolvidos no momento de sua produção.

Embora várias mulheres apareçam em $O$ instante certo, poucas são fotógrafas. No ensaio “As múltiplas vidas de Lee Miller" (Ibid., 97-110) é apresentada a modelo e, mais tarde, fotógrafa que deixou um acervo de "60 mil negativos originais, 20 mil imagens em folhas de contato ou cópias em papel, além de manuscritos e documentos" (Ibid., 110). Outra figura é a babá fotógrafa, a quem dedica dois textos: "O enigma Vivian Maier" partes I e II (Ibid., 221-233). Apesar de socialmente retraída, quando acompanhada da Rolleiflex portátil, Maier fotografava uma multiplicidade de desconhecidos nas ruas dos centros urbanos próximos ao seu local de trabalho. Sua obsessão por fotografar era tal que deixou mais de $100 \mathrm{mil}$ negativos, centenas de rolos não revelados, 1,5 mil slides e mais de trinta curtas de $8 \mathrm{~mm}$ (Ibid., 226).

Aluna de Manuel Álvares Bravo, com quem aprendeu a esperar o tempo passar e nesse ínterim algo acontecer, a fotógrafa mexicana Graciela Iturbide é apresentada em "Pássaro Solitário" (Ibid., 343-353). Conhecida 
por borrar em seus ensaios as fronteiras entre arte e documento, a obra de Iturbide passou a ser conhecida a partir da publicação do ensaio Los que viven em la arena (1979). Trata-se de um trabalho documental sobre os índios seris que foi bem recebido pela crítica visual, mas frustrou antropólogos preocupados com a "abordagem emocional das imagens" (Ibid., 345). Para eles, as legendas usadas como Mujer Angel, nome da foto que trouxe fama à fotógrafa, não informavam sobre o que, afinal, tratava as imagens. Iturbide respondeu: "Não sou antropóloga nem socióloga. Tiro fotos pelo gosto de fazê-las, nunca fotografo nada apenas para documentar" (Ibid., 343).

Enquanto Miller foi, como explica Harazim, dissecada pela câmera muitas vezes, inclusive por seu pai (Ibid., 100), além de aprender com ele noções de enquadramento, perspectiva e ampliação - o que a levou a fazer muitas imagens autorais (Ibid., 102) -, Evelyn MacHale, ao contrário, eternizou-se por meio de sua única imagem publicada, que aparece no ensaio a "Foto imortal" (Ibid., 11-17). MacHale morreu aos 23 anos e seu mórbido retrato não apenas abre o livro, mas anuncia como a morte humana é um assunto para a fotografia e um tema no livro de Harazim. Assim, não faltam cenas tocantes de morte e mortos, reproduzidas ou sugeridas em vários dos textos.

A presença da morte em certas fotos ajudou a mudar o curso das sociedades, como Execução em Saigon, de 1968, historiada em "A chave" (Ibid., 303-309). Para os profissionais sul-africanos do Clube do Bangue-Bangue, cuja vida em grupo é descrita em "Abutres ou heróis?" (Ibid., 19-29), as chacinas se tornaram o personagem central do fim do processo de dissolução do apartheid. Acompanhando a narrativa, a sensação é que as guerras instalam uma total confusão entre pessoas e coisas. Nessas ocasiões, seres humanos viram uma espécie de resíduo ou lixo do conflito, conforme afirmou um dos fotógrafos sobreviventes do Clube, Greg Marinovitch: "Cadáveres são objetos estranhos" (Ibid., 25). Essa estranheza reaparece no ensaio "O cidadão Meeropol" (Ibid., 355-366), no qual uma das imagens discutidas faz alusão à prática social dos linchamentos de pessoas negras que ocorreram quase sem trégua em muitos estados do Sul dos Estados Unidos, entre o fim do século XIX até 1968 (Ibid., 359). 0 cidadão referido no título é Abel Meeropol, branco e judeu que escreveu Strange Fruit (1938), canção eternizada na voz de Billie Holiday. A letra demonstrou o assombro de Meeropol diante da naturalidade com que se praticavam violências contra a população negra.

No mesmo espírito, mas com foco na experiência feminina do racismo, o ensaio "Ódio revisitado" (Ibid., 295-301) descreve duas mulheres - Elizabeth Eckford e Hazel Bryan - que no ano da imagem, 1957, tinham apenas quinze anos de idade. A cena é uma síntese da sociedade 
norte-americana em um combate que, mais de sessenta anos depois, não garantiu direitos plenos ao negro estadunidense. Harazim conta que "A foto ganhou força, tornando-se uma bandeira para toda uma geração de atletas, advogados, professores negros" (Ibid., 299). Ao trazer a imagem de volta e comentá-la, a autora revela a atualidade das dores produzidas pelo racismo ao adentrar a trajetória de vida dessas mulheres após a divulgação da foto.

O instante certo termina com "Relembranças" (Ibid., 375-382), texto aberto com uma foto de Dorrit Harazim feita no Camboja, em 1970, e que, embora encerre o livro, também poderia iniciá-lo. Ela explica como chegou a certas imagens, fala do seu desejo de comentá-las e do que descobriu sobre elas. Seu gosto por desenterrar histórias, descobrir quem é a pessoa retratada, saber sobre o ambiente que acolheu ou recusou inicialmente uma foto, enfim, perscrutá-la para além do clique tem a ver com sua concepção do que seja, afinal, uma fotografia. E ensina: "quando olhamos para uma fotografia, vemos nela, também, o reflexo de quem somos" (Ibid., 377).

\section{REFERÊNCIAS BIBLIOGRÁFICAS}

Assmann, Aleida. 2011. Espaços da recordação: formas e transformações da memória cultural. Campinas: Unicamp.

Benjamin, Walter. 1994. Pequena história da fotografia. In Magia e técnica, arte e política: ensaios sobre literatura e história da cultura, $7^{\text {a }}$ ed, vol. 1: 91-107. São Paulo: Brasiliense.

Bispo, Alexandre Araújo. 2012. Mapas fotográficos: memória familiar, sociabilidade e transformações urbanas em São Paulo (1920-1960). Dissertação de mestrado, Universidade de São Paulo, São Paulo.

Bril, Stefânia. 1987. Notas: vinte e nove mestres da fotografia. São Paulo, Prêmio.

Bruno, Fabiana. 2009. Fotobiografia: por uma metodologia da estética em antropologia. Tese de doutorado, Universidade Estadual de Campinas, Campinas.

Camargo, Ana Maria de Almeida e Silvana Goulart. 2007. Tempo e circunstância: a abordagem conceitual dos arquivos pessoais: procedimentos metodológicos adotados na organização dos documentos de Fernando Henrique Cardoso. São Paulo: Instituto Fernando Henrique Cardoso.

Edwards, Elizabeth. 2012. Objects off affect: photography beyond the image. Annual Rewiew of Anthropology, vol. 41: 221-234. 
Harazim, Dorrit. 2016. O instante certo. São Paulo: Companhia das Letras.

Leite, Miriam Moreira. 2001. Retratos de familia: leitura da fotografia histórica, $3^{\mathrm{a}}$ ed. São Paulo: Edusp.

Travancas, Isabel Siqueira, Joëlle Rachel Rouchou e Luciana Heymann, orgs. 2013. Arquivos pessoais: reflexões multidisciplinares e experiência de pesquisa. Rio de Janeiro: FGV.

\section{ALEXANDRE ARAÚJO BISPO}

Bacharel em Ciências Sociais, Mestre (2012) e doutorando em Antropologia Social pela Universidade de São Paulo. Desenvolve pesquisas sobre recebido a relação entre biografia, práticas culturais,cultura visual, consumo de 02.08.2017 bens visuais em ambiente urbano, fotografia e memória. Membro do aprovado grupo de pesquisa CNPq Coletivo ASA: Arte, saberes e antropologia lidera22.10.2017 do pela professora Dra Fernanda Arêas Peixoto. 